\title{
Metabolic Syndrome Among Physicians: A Pilot Study from Chattogram, Bangladesh
}

Anisul Awal ${ }^{1}$

Farid Uddin Ahmed ${ }^{2 *}$

'Department of Cardiology Chittagong Medical College Chattogram, Bangladesh.

${ }^{2}$ Department of Community Medicine Rangamati Medical College Rangamati, Bangladesh.

\author{
*Correspondence to: \\ Dr. Farid Uddin Ahmed \\ Assistant Professor \\ Department of Community Medicine \\ Rangamati Medical College \\ Rangamati, Bangladesh. \\ Mobile : +8801727 789700 \\ Email : fuahmed34@yahoo.com
}

Date of Submission : 10.05 .2021 Date of Acceptance : 16.06 .2021

\begin{abstract}
Background : Although the information on Metabolic Syndrome (MetS) in the general population from different parts of Bangladesh is available, the information regarding the same is scarcely available from physicians of Bangladesh. This study was aimed to assess the prevalence of MetS among physicians working at Chattogram Medical College Hospital, Bangladesh.
\end{abstract}

Materials and methods : Data was collected for this cross-sectional study from 255 working physicians of Chittagong Medical College Hospital in 2018. The participants filled a structured questionnaire followed by physical and biochemical measurements including waist circumference, blood pressure, lipid profile, and fasting blood glucose. National Cholesterol Education Program's Adult Treatment Panel III report (ATP III) defines criteria were used to identify physicians with the MetS.

Results : Among 255 participants (males - 192 and females - 63), 100 (39.2\%) were with MetS. Prevalence of same was higher in females (41.3\%) than males (38.5\%). The elderly physicians ( $>40$ years) had a higher prevalence compared to the younger ( $\leq 40$ years) physicians [72 (50.3\%) vs. 28 (25.0\%)]. In the males, low High-Density Lipoproteins-Cholesterol (HDL-C) was the major contributor to the prevalence of MetS followed by high blood pressure. However, in females, low HDL-C and greater waist circumference contributed the maximum to Mets.

Conclusion : This study showed a high prevalence of MetS among physicians of Bangladesh, and thereby warrants the urgent implementation of preventive health care strategies to reduce both morbidity and mortality related to this medical problem. Further studies ought to focus on the working conditions and lifestyles of individuals in these high-risk groups.

Key words: Bangladesh; Metabolic syndrome; Physician.

\section{INTRODUCTION}

Metabolic Syndrome (MetS) variously known also as syndrome X, insulin resistance etc. is defined by WHO as a pathologic condition characterized by abdominal obesity, insulin resistance, hypertension and hyperlipidemia ${ }^{1}$. It is generally agreed that having three or more of these aetiologically linked cardiometabolic risk factors increase the risk of developing multiple chronic diseases such as cardiovascular disease, type 2 diabetes, arthritis, chronic kidney disease, schizophrenia, several types of cancer and early death ${ }^{2}$.

The worldwide prevalence of MetS in the adult population is on the rise with an estimated prevalence of $20-25 \%{ }^{3}$. Recent estimate indicates the weighted pooled prevalence of MetS is between 20.0 and $37.0 \%$ depending on the criteria used to define MetSin Bangladesh which was slightly higher than the prevalence estimated around the world ${ }^{3,4}$ 
Though a handful of studies were conducted about MetS in the Bangladeshi population, the information regarding the same is scarcely available from doctors of Bangladesh ${ }^{5-7}$. Study in other countries noticed that MetS is still a significant public health problem in the educated population including those of doctors, especially the younger ones ${ }^{8}$. Since doctors are considered to be representing a highly educated mass of the population, their awareness, and knowledge regarding the health consequences of lifestyle changes are generally expected to be high. With such a background in mind, this study was planned to assess the frequency of MetS among the doctors of a tertiary hospital of Chattogram, Bangladesh.

\section{MATERIALS AND METHODS}

This cross-sectional, single-center observational study was conducted at Chittagong Medical College Hospital (CMCH) a tertiary care hospital and medical college in Bangladesh over 6 months (January 2018 to June 2018) after obtaining permission from the Ethical Review Committee of Chittagong Medical College.

A total of 255 doctors working in $\mathrm{CMCH}$, participated and were included in this study after getting their consent. Simple questionnaires on age, prior medical history of drug intake, diabetes mellitus, or hypertension was answered by the doctors. Subjects with any coexisting serious diseases, those who refused to participate were excluded from the study. All participants were subjected to anthropometric measurements such as height, weight, and Waist Circumference (WC) using standard procedures and blood pressure measurement as described elsewhere ${ }^{9}$. Fasting blood samples were taken for estimation of fasting plasma glucose, triglycerides, total cholesterol, high-density lipoproteins, low-density lipoproteins. MetS were defined according to Modified National Cholesterol Education Program-Adult Treatment Panel III (NCEP-ATP III) criteria $^{10}$. Table I describes Modified NCEP ATP III criteria for MetS screening. The presence of at least 3 of the 5 risk factors defines MetS in an individual.

Table I : Modified NCEP ATP III criteria for MetS screening

$\begin{array}{ll}\text { Risk factors } & \text { Cutoff points } \\ \text { Waist circumference } & \text { Males }>90 \mathrm{~cm}, \text { females }>80 \mathrm{~cm} \\ \text { SBP/DBP } & \geq 130 \mathrm{~mm} \text { of } \mathrm{Hg} \text { and } / \text { or } 85 \mathrm{~mm} \\ & \text { of } \mathrm{Hg} \text { or on treatment for HTN } \\ & \geq 150 \mathrm{mg} / \mathrm{dL} \\ \text { Triglycerides } & <40 \mathrm{mg} / \mathrm{dl}-\mathrm{male},<50 \mathrm{mg} / \mathrm{dL} \\ \text { HDL-C } & - \text { females } \\ & \geq 100 \mathrm{mg} / \mathrm{dL}, \text { or } \\ \text { Fasting plasma sugar } & \text { on treatment for diabetes }\end{array}$

SBP: Systolic Blood Pressure, DBP: Diastolic Blood Pressure, HDL-C: High-Density Lipoprotein Cholesterol.
Data were analyzed by SPSS version- 23 on a computer. Categorical variables were expressed as frequency and percentage. Prevalence of MetS in total study subjects as well as two age groups and male and female were determined at 95\% Confidence Interval (CI). Chi-square tests were performed to determine overall differences in the frequencies of categorical variables between male and female doctors. Statistical significance will be defined as $\mathrm{p}<0.05$.

\section{RESULTS}

Out of 255 doctors, there were 192 male and 63 female doctors. $56.1 \%$ of them belong to more than 40 years age group. About $60 \%$ of the doctors were obese as per BMI criteria and $73 \%$ had elevated waist circumference indicating central obesity. Prevalence of hypertension and diabetes were $40 \%$ and $17.6 \%$ respectively. Males showed a significantly higher percentage of hypertension than the females, more percentage of females were seen having increased BMI and WC (Table II).

Table II: Demographic and clinical charecteristics.

\begin{tabular}{|c|c|c|c|c|}
\hline Characteristics & $\begin{array}{r}\text { Total } \\
(\mathrm{n}=255)\end{array}$ & $\begin{array}{r}\text { Male } \\
(\mathrm{n}=192)\end{array}$ & $\begin{array}{r}\text { Female } \\
(n=63)\end{array}$ & $\mathrm{p}$ value \\
\hline \multicolumn{5}{|l|}{ Age group } \\
\hline$\leq 40$ years & $112(43.9 \%)$ & $80(41.7 \%)$ & $32(50.8 \%)$ & 0.021 \\
\hline$>40$ years & $143(56.1 \%)$ & $112(58.3 \%)$ & $31(49.2 \%)$ & \\
\hline \multicolumn{5}{|l|}{$\operatorname{BMI}\left(\mathrm{kg} / \mathrm{m}^{2}\right)$} \\
\hline Normal (18.0 to 22.9) & $42(16.5 \%)$ & $28(14.6 \%)$ & $14(22.2 \%)$ & 0.039 \\
\hline Overweight (23.0 to 24.9) & $61(23.9 \%)$ & $53(27.6 \%)$ & $8(12.7 \%)$ & \\
\hline Obese $(\geq 25)$ & $152(59.6 \%)$ & $111(57.8 \%)$ & $41(65.1 \%)$ & \\
\hline \multicolumn{5}{|l|}{ Waist circumference (cm) } \\
\hline Normal & $70(27.5 \%)$ & $65(33.9 \%)$ & $5(7.9 \%)$ & $<0.001$ \\
\hline Elevated & $185(72.5 \%)$ & $127(66.1 \%)$ & $58(92.1 \%)$ & \\
\hline Hypertensive & $102(40.0 \%)$ & $85(44.3 \%)$ & $17(27.1 \%)$ & 0. \\
\hline Diabetic & $45(17.6 \%)$ & $37(19.3 \%)$ & $8(12.7 \%)$ & 0.24 \\
\hline
\end{tabular}

The most common abnormality in lipid profile was low HDL-C $(71.8 \%)$ followed by elevated TG $(51.8 \%)$. Males showed a significantly higher percentage of elevated TG than females (Table III)

Table III : Lipid profile of the participants stratified by sex

$\begin{array}{lrrrr}\text { Lipid profile (Unit) } & \begin{array}{r}\text { Total } \\ (\mathbf{n = 2 5 5})\end{array} & \begin{array}{r}\text { Male } \\ (\mathbf{n}=\mathbf{1 9 2})\end{array} & \begin{array}{r}\text { Female p value } \\ (\mathbf{n}=63)\end{array} & \\ \begin{array}{l}\text { Elevated cholesterol } \\ (\geq 200 \mathrm{mg} / \mathrm{dl})\end{array} & 97(38.0 \%) & 75(39.1 \%) & 22(34.9 \%) & 0.56 \\ \begin{array}{l}\text { Elevated triglyceride } \\ (\geq 150 \mathrm{mg} / \mathrm{dl})\end{array} & 132(51.8 \%) & 107(55.7 \%) & 25(39.7 \%) & 0.03 \\ \begin{array}{l}\text { Elevated LDL-C } \\ (\geq 130 \mathrm{mg} / \mathrm{dl})\end{array} & 100(39.2 \%) & 79(41.1 \%) & 21(33.3 \%) & 0.27 \\ \begin{array}{l}\text { Low HDL-C } \\ (\text { Male: }<40, \text { Female }<50 \mathrm{mg} / \mathrm{dl})\end{array} & 183(71.8 \%) & 135(70.3 \%) & 48(76.2 \%) & 0.36\end{array}$


LDL-C: Low Density Lipoprotein Cholesterol; HDL-C: High Density Lipoprotein Cholesterol.

Figure 1 shows that, the overall prevalence of MetS in the study was $39.2 \%$ (95\% CI: $33.2 \%$ - $45.5 \%)$.

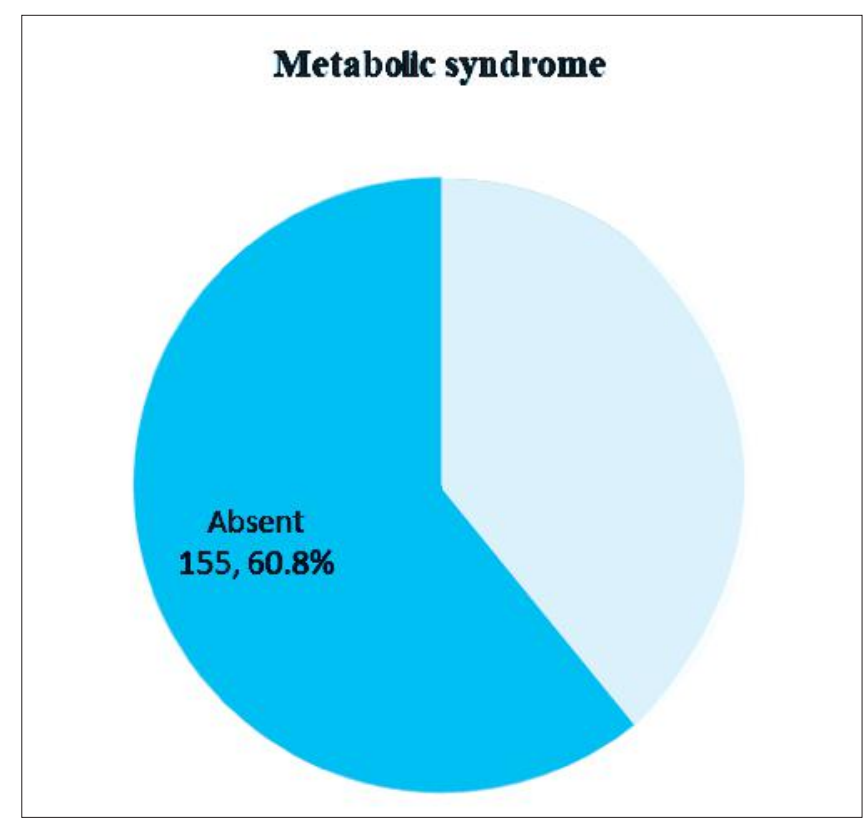

Figure 1: Prevalence of MetS among 255 physicians

Of the 192 males, 74 (38.5\%) were screened to have MetS. Similarly, $26(41.3 \%)$, of 63 females had MetS. MetS were more prevalent $(50.3 \%)$ in the age group $>40$ years than that of $\leq 40$ years group $(25 \%)$ which was statistically significant $(\mathrm{p}<0.001)$ as shown in Table IV.

Table IV : Prevalence of MetS among 255 physicians stratified by age groups and gender

\begin{tabular}{lrrrr} 
Parameters & \multicolumn{2}{c}{ Age group } & \multicolumn{2}{c}{ Gender } \\
& $\leq 40$ years & $>\mathbf{4 0}$ years & Male & Female \\
Frequency & 112 & 143 & 192 & 63 \\
MetS present & 28 & 72 & 74 & 26 \\
Proportion & 25.0 & 50.3 & 38.5 & 41.3 \\
$95 \%$ CI of proportion & $17.3-34.1$ & $41.9-58.8$ & $31.6-45.8$ & $29.1-54.4$ \\
p value & \multicolumn{2}{c}{$<0.001$} & \multicolumn{2}{c}{0.700}
\end{tabular}

\section{DISCUSSION}

Information regarding the burden of MetS is scarcely available in Bangladesh. This information is imperative for monitoring MetS and could contribute to planning and prevention strategies to tackle this problem. This study was undertaken to find out the magnitude of doctors having MetS in a tertiary care health institute of Chattogram, Bangladesh. Current study demonstrated that, the prevalence of MetS among doctors was $39.2 \%$ (95\% CI:33.2\% - 45.5\%). This was higher than the estimated prevalence of MetS in the general population of Bangladesh. The estimated weighted pooled prevalence of MetS was 37\% [95\% CI: 29\% - 46\%] in studies conducted in the general population that used Modified NCEP ATP III criteria as revealed by a recent meta-analysis ${ }^{4}$. Decades ago, Baul et al found that the prevalence of MetS was $38.8 \%$ in a total of 500 doctors from Bangladesh ${ }^{7}$. Similarly, Manjareeka et al. from Pakistan also observed that among 170 physicians working at a tertiary hospital $37.65 \%$ were diagnosed to have ${ }^{8}$. This higher prevalence of MetS among doctors than the general population may be attributed to higher socioeconomic status, less physical activity, and a more stressful working atmosphere for the former sector of the population.

The prevalence of MetS in this study showed a higher value for females $(41.3 \%)$ than for males $(38.5 \%)$ without any statistically insignificant, while a reverse trend was observed in earlier studies conducted on physicians ${ }^{7,8,11}$. However, our findings were supported by the findings of a meta-analysis which included studies conducted among the general population of Bangladesh where the MetS are higher in females $(32 \%)$ compared to males $(25 \%)^{4}$. Lower prevalence of MetS in this study may be due to increasing health consciousness among male doctors.

Chowdhury et al stated that the overall prevalence of MetS increases $0.4 \%$ for every one-year increase in the mean age of the study participants in the Bangladeshi population. Such an increase in MetS prevalence over the age of the participants was quite similar in males and females ${ }^{4}$. Our study confirms this agedependent prevalence of MetS among doctors of Bangladesh. This study demonstrated central obesity (As determined by waist circumference) as the most frequent individual component of MetS with an overall prevalence of $72.5 \%$, followed by low HDL cholesterol (71.8\%) and elevated fasting $\mathrm{TG}(51.8 \%)$. The underlying factors behind the increased prevalence of obesity, low HDL, high TG among physicians could be multifarious. The fascination for adopting a western lifestyle could influence such high prevalence ${ }^{12,13}$. Other plausible causes might be lifestyle changes such as physical inactivity, changes in diet, and job-related stress.

\section{LIMITATIONS}

The present study has a few limitations. First, the study participants are working in a single tertiary care hospital and medical college. Thus, it is difficult to generalize the findings to all the doctors of the community. Second, though few nutritional details of the subjects were collected, correlation with findings could not be done. Third, we did not find out the prevalence of MetS in the general population. Hence, a comparison of findings of the study group with the control group has not been done. Despite the limitations, this study is very few of its kind in Bangladesh to explore the burden of MetS among the doctors in southern Bangladesh.

\section{CONCLUSIONS}

It can be concluded that the prevalence of the MetS is alarmingly high among the doctors of Bangladesh. In the present study, the young male doctors have a greater prevalence of MetS than the older and females. MetS is still a significant public health problem in the educated population including those of doctors, especially the younger ones. 


\section{RECOMMENDATION}

Current study recommends urgent attention from both the clinical and public health viewpoint to this high prevalence of MetS among doctors of Bangladesh. Hence strategies aimed at primary prevention are required to mitigate a further increase in the prevalence and for the reduction of the morbidity and mortality associated with MetS. Further probes with the involvement of multi-centers and assessment of other competing risk factors appear necessary to highlight the details of MetS profile among the doctors.

\section{ACKNOWLEDGMENT}

Authors acknowledged the help of Baximco Pharmaceutical limited and CSCR diagnostic center of Chattogram regarding laboratory investigations.

\section{DISCLOSURE}

All the authors declared no competing interest.

\section{REFERENCES}

1. Alberti KG, Eckel RH, Grundy SM, Zimmet PZ, Cleeman JI, Donato KA et al. Harmonizing the metabolic syndrome: a joint interim statement of the International Diabetes Federation Task Force on Epidemiology and Prevention; National Heart, Lung, and Blood Institute, American Heart Association, World Heart Federation, International Atherosclerosis Society and International Association for the Study of Obesity. Circulation. 2009;120(16):1640-1645.

2. Swarup S, Goyal A, Grigorova Y. Metabolic Syndrome. In: StatPearls [Internet]. Treasure Island (FL): StatPearls Publishing. 2021. Available from: https://www.ncbi.nlm.nih.gov/books/NBK459248/

3. International diabetes federation, the IDF consensus worldwide definition of the metabolic syndrome. Available from: https://www.idf.org/e-library/consensus-statements/60-idfconsensus-worldwide-definitionof-the-metabolic-syndrome.

4. Chowdhury MZI, Anik AM, Farhana Z, Bristi PD, Abu Al Mamun BM, Uddin MJ, et al. Prevalence of metabolic syndrome in Bangladesh: A systematic review and meta-analysis of the studies. BMC Public Health. 2018;18(1):308.

5. Mainuddin A, Choudhury K, Ahmed K, Akter S, Islam N, Masud J. The metabolic syndrome: Comparison of newly proposed IDF, modified ATP III and WHO criteria and their agreements. Cardiovascular Journal. 2013;6:17-22.

6. Rahim M, Khan AA, Sayeed M, Akhtar B, Nahar Q, Ali S et al. Metabolic syndrome in rural Bangladesh: Comparison of newly proposed IDF, modified ATP III and WHO criteria and their agreements. Diab Metabolic Syndrome. 2007;1:251-257.

7. Baul S, Parvin D, Hossain S, Hadiuzzaman M, Mollah F, Hoque M. Evaluation of Some Predictors of Metabolic Syndrome in an Important Group of Health Care Providers of Bangladesh. BJMB. 2019;11(1):26-26.

8. Manjareeka M, Mishra S, Nayak PK, Patro S, Mishra J, Dash S. Metabolic syndrome among doctors: a pilot study from Odisha. Asian J Pharm Clin Res.2018;11(10): 294-297.

9. Awal A, Tareq N, Bhattacharjee B, Chowdhury I, Dey A, Das PK et al. Prediction of 10 Years and Lifetime Atherosclerotic Cardiovascular Disease (ASCVD) Risk Among Working Physician of CMCH. University Heart Journal.2017;12(2):68-75.

10. Grundy SM, Cleeman JI, Daniels SR, Donato KA, Eckel RH, Franklin BA, et al. Diagnosis and management of the metabolic syndrome: An American Heart Association/National Heart, Lung and Blood Institute Scientific Statement. Circulation. 2005;112(17):2735-2752.

11. Ramachandran A, Snehalatha C, Yamuna A, Murugesan N. High prevalence of cardiometabolic risk factors among young physicians in India. J Assoc Physicians India. 2008;56:17-20.

12. Low WY, Lee YK, Samy AL. Non-communicable diseases in the Asia-Pacific region: prevalence, risk factors and community-based prevention. Int J Occup Med Environ Health. 2015;28:20-26.

13. Misra A, Khurana L. The metabolic syndrome in South Asians: Epidemiology, determinants and prevention. Metab Syndr Relat Disord. 2009;7:497-514. 